\title{
Numerical Studies of the Rotational Stiffness of Purlin-Sheeting System
}

\author{
Feiliang Wang ${ }^{1} \cdot$ Hanwen Zhang ${ }^{2}$ (C) Jian Yang ${ }^{1} \cdot$ Li Bai $^{1} \cdot$ Chong Ren ${ }^{3}$
}

Received: 11 August 2017 / Accepted: 3 March 2018 / Published online: 8 June 2018

(c) The Author(s) 2018

\begin{abstract}
In light-gauged steel purlin-to-sheeting roof systems, the attached sheeting can provide rotational restraints to the purlin. The magnitude of the additional rotational stiffness offered by the sheeting will affect the load bearing capacity of the purlin. The current design method in Eurocode3 (EC3) is less accurate in predicting the purlin-sheeting rotational stiffness as it neglects the effect of wall thickness of the purlin. An integral model is introduced based on the finite element method. Comparisons are made between numerical results and existing experiments and a good agreement is observed. Parametric studies are conducted based on the validated model to investigate the influences of geometric dimensions on the rotational stiffness. Two modified coefficients are proposed for calculating the rotational stiffness based on the codified formulae in EC3, where the effect of the wall thickness and the flange width of the purlin are both considered.
\end{abstract}

Keywords Analytical method $\cdot$ Codes $\cdot$ Finite element method (FEM) $\cdot$ Non-linear analysis $\cdot$ Parametric analysis $\cdot$ Thinwalled members

\section{Introduction}

Roof systems with cold-formed steel (CFS) purlins attached to corrugated sheeting are widely used due to its shorter construction time. Traditional CFS purlin cross-section types include $\mathrm{C}$-section and $\mathrm{Z}$-section; the former is usually applied on flat roofs and the latter is generally used on the pitch roofs. $\Sigma$ purlin, which evolved from $\mathrm{C}$-section purlin but with two more insets, has been proposed since it has better torsional resistance capacity. Moreover, open-section purlins are known to be vulnerable to various buckling modes. The attachment of corrugated sheeting can provide lateral restraints to the purlins and therefore enhance the overall load bearing capacity.

In recent decades, the screw connections of CFS sections have been studied extensively by various researchers

Hanwen Zhang

hwz257@bham.ac.uk

1 School of Naval Architecture, Ocean and Civil Engineering, Shanghai Jiao Tong University, Shanghai, China

2 School of Engineering, University of Birmingham, Birmingham, UK

3 Department of Civil Engineering, Shanghai University, Shanghai, China through experimental and numerical approaches (Tan et al. 1996; Mills and Laboube 2004; Kwon et al. 2006; Bambach and Rasmussen 2007; Fiorino et al. 2007; Gutierrez et al. 2011). Special considerations of the connection performance of purlins attached to sheeting have been implemented into design standards such as EC3 (Eurocode 2006). In the code, the lateral and rotational restraints provided by the sheeting are considered as lateral and rotational springs respectively, and the spring stiffness is obtained analytically. However, the method in EC3 for modeling rotational stiffness has been criticized over the last decades due to its relatively low accuracy (Vrany 2002). Hence modifications to the current design standard are required and the topic has drawn increasing interests from researchers. An analytical model was developed in (Vrany 2006) to determine the effect of external loading on the rotational restraint. It was found that a higher stiffness of the rotational restraint provided by sheeting results in a reduction of stress in the free flange and a reduction of buckling length in hogging moment areas. Mechanicsbased expressions were introduced by (Gao and Moen 2012) for calculating the rotational restraint provided by through-fastened metal panels to Z- and C-section girts or purlins. The equations considered the effect of local panel deformation at a screw, and the girt or purlin flange 
bending at a through-fastened connection. An analytical formulae was derived by Ren et al. (2012) to calculate the bending stress of the partially restrained channel-section purlins by using the classic bending theory of thin-walled beams. In order to further consider the interactional effect at screw points and the effect of loading directions, an improved analytical method based on experimental studies was proposed in Zhao et al. (2014) to predict the rotational stiffness of cold-formed $\mathrm{Z}$ and $\Sigma$ purlin/sheeting systems.

As open sections such as channel, zed, angle and sigma section are vulnerable to local and distortional buckling (Li 2009; Ye et al. 2002b; Yang and Liu 2012b; Huang and Zhu 2016; Bai et al. 2017; Huang et al. 2018), the restraining effect provided by sheeting can be used for improving buckling resistance of the CFS purlin. For the purlin-sheeting system under uplift loading scenario, it was found that translational spring stiffness can affect the local buckling of purlin while rotational spring stiffness has influence on lateral-torsional buckling, and the rotational spring stiffness has no influence compared to the translational spring stiffness on the maximum tensile and compressive stress (Ye et al. 2002a, 2004). Moreover, the influence of the initial geometric imperfections on the purlin performance was found only in purlins of medium or long length with no or low rotational spring stiffness (Zhu et al. 2013). For the purlin subjected to pure bending, the lateral restraint provided by the sheeting has almost no effect on the lateral-torsional buckling of the member ( $\mathrm{Li}$ 2004). The influence of lateral restraint provided by cladding on the lateral-torsional buckling of Z-purlin beams was examined in Chu et al. (2005) by using the energy method. Moreover, an analytical model that describes the bending and twisting behavior of partially restrained CFS purlins subjected to uplift loading was further developed by Li et al. (2012). For a fully restrained thin-walled channel or $\mathrm{Z}$ section beam subjected to uplift loading, it will not buckle in lateral-torsional mode, but may exhibit a web-flange distortional buckling mode (Yuan et al. 2014). The studies have been extended experimentally and numerically regarding the restrain of sandwich panels to the buckling of purlins. Analysis of the experimental results reveals that the rotational stiffness of sandwich panels depends significantly on the type of beam, the type of sandwich panel and the magnitude of the vertical gravity load as well as the modulus of elasticity of the sandwich core material (Durr et al. 2011). The test approach defined by EN 1993-1-3 Annex A5 has been reviewed and an improved full scale experimental program was proposed to consider more realistic restrain conditions (Gajdzicki and Goczek 2015). A significant rate of torsional restraint provided to thin-walled members by sandwich panels under uplift load can be observed (Balazs et al. 2016) and the rate of thinwalled beam capacity increase depends on the number of the fasteners (Ciesielczyk and Studziński 2017).
A series of laboratory tests were conducted for determining the relationship between failure modes, ultimate loads and loading patterns of C, Z, Zeta, Hat (Laine and Tuomala 1999) and $\Sigma$ section (Yang and Liu 2012a). A full model (Lucas et al. 1997a) and simplified models (Lucas et al. 1997b; Vieira et al. 2010) were developed based on nonlinear finite element method (FEM) to study the behavior of purlin-sheeting system and rotational stiffness with various sections. It was shown that the simplified model included only the purlin was able to account for the restraining action of the sheeting by modeling this effect as shear and rotational springs located at the purlin to sheeting connection points. It was validated by Chung and Ho (2005), Katnam et al. (2007), Kim et al. (2007), Kujawa and Szymczak (2014), Liu et al. (2015) and Gajdzicki and Goczek (2015) that the numerical approach was indeed a dependable tool for investigating the CFS connection issues.

In this paper, a full model established numerically for predicting the rotational stiffness provided by corrugated sheeting to the sigma purlin is presented. The model is validated against existing experiments. Parametric studies are conducted to reveal the effect of varying the geometric dimensions of the purlin and the interval of the screws on the rotational stiffness. Based on the numerical results, compensation coefficients are proposed to the current EC3 approach to calculating the rotational stiffness of $\Sigma$ purlin-corrugated sheeting system.

\section{Experimental and Analytical Studies}

\subsection{Laboratory Tests}

Laboratory tests of purlin-sheeting system were conducted and the results were presented in the companion paper (Zhao et al. 2014). The setup of the experiment was conducted according to requirements stated in Annex 5 of EC1993-1-3 (Eurocode 2006). During the test, the sigma purlin with a length of $1 \mathrm{~m}$ was attached to the corrugated sheeting by five self-drilling screws with a diameter of $5.5 \mathrm{~mm}$. The screws were located at the centerline of one flange of the purlin flange connected to the sheeting's trough, as shown in Fig. 1. The point load was distributed on the free flange by using a steel bracket with 7 bolts. In the test, the sheeting was fixed on the ground via bottom cleats and $M 10$ bolts. Two scenarios: face-up (gravity loading case) and face-down (uplift loading case), were conducted during the test as shown in Fig. 1. The configurations of tested purlin sections and corrugated sheeting are shown in Figs. 2 and 3, where $W$ is the total crosssection depth; $F$ is the flange width; $t$ is the thickness; $L$ is the lip length; $O$ is the depth of the top and bottom parts of the web adjacent to the flanges in the sigma section; 

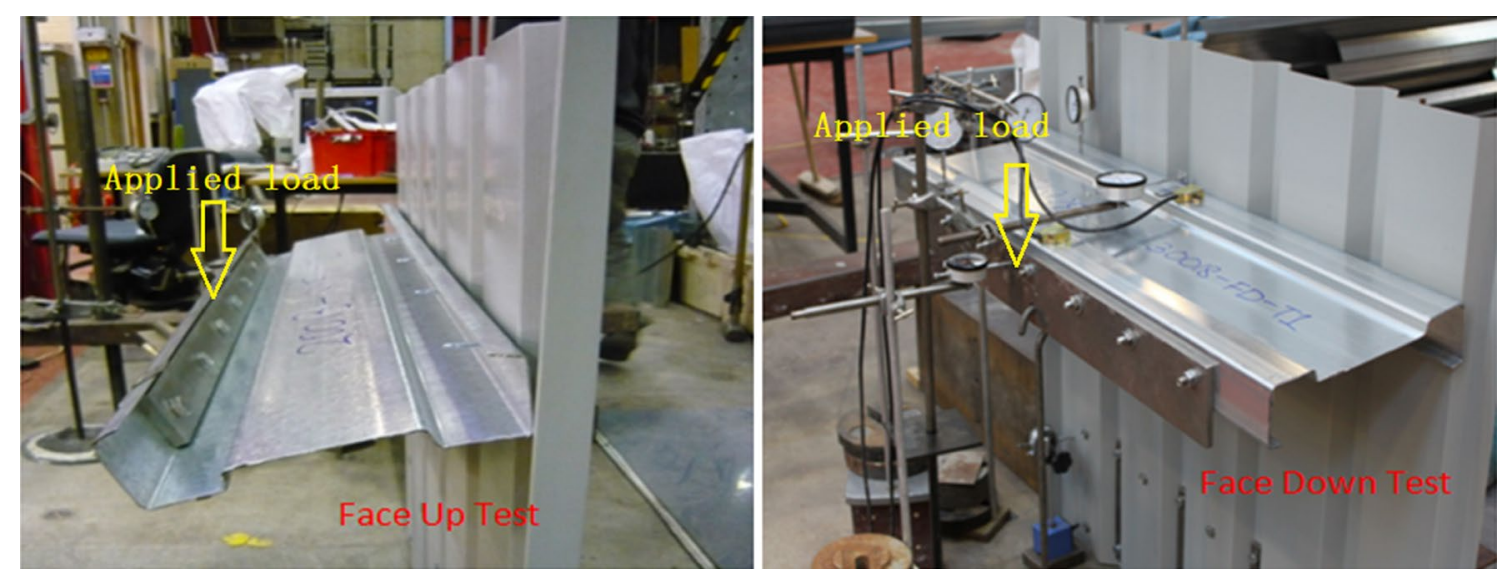

Fig. 1 Test setup

Fig. 2 Diagram of $\Sigma$-, C- and Z-sections. a $\Sigma$-section, b C-section, c Z-section

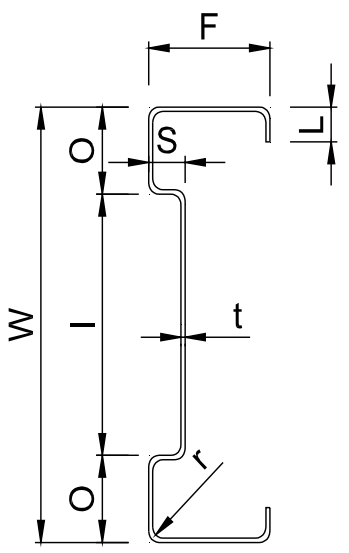

(a)

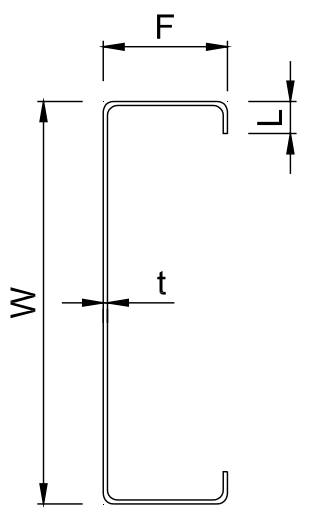

(b)

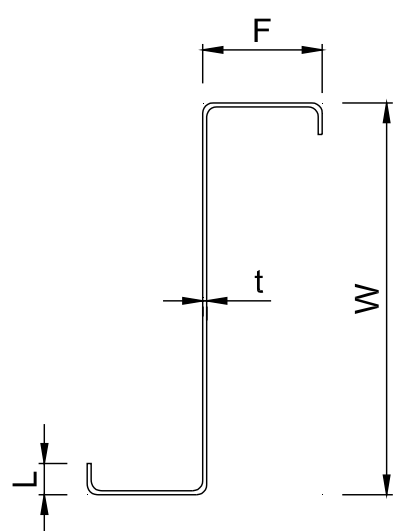

(c)
$I$ is the middle part of the modified web in the sigma section; $S$ is the width of the inward bend of the web and $r$ is the corner radius. The cross-section dimensions of each specimen are provided in Tables 1 and 2. The material properties of the specimen were obtained from tensile coupon tests (BSI 2009). The coupons were cut from the flat region of CFS $\Sigma$-sections and the tests were conducted by using a SANS 20t displacement controlled test machine (see Fig. 4). The average stress-strain curve is shown in Fig. 5. The laboratory results of rotational stiffness $C_{D, A}$ can be calculated by:

$C_{D, A}=\frac{M}{\theta_{1}}$

where $C_{\mathrm{D}, \mathrm{A}}$ is the rotational stiffness of the connection between the sheeting and the purlin, $M$ is the applied moment per unit width of the sheeting and $\theta_{1}$ is the resulting rotation angle of the purlin at the connection point.

\subsection{Analytical Design Approach in EC3}

The analytically derived equation for calculating the total rotational stiffness $\left(C_{D}\right)$ provided by the sheeting to the purlin is specified in Eq. (10.14) of EC3 (Eurocode 2006) and is given by:

$C_{D}=\frac{1}{\left(1 / C_{D, A}+1 / C_{D, C}\right)}$,

where $C_{D, A}$ is the rotational stiffness of the connection between the sheeting and the purlin; and $C_{D, C}$ is the rotational stiffness corresponding to the flexural stiffness of the sheeting, which is negligible as the value of $C_{D, C}$ is considered to be much larger than $C_{D, A}$. The value of $C_{D, A}$ can be determined by:

$C_{D, A}=C_{100} \cdot k_{b a} \cdot k_{t} \cdot k_{b R} \cdot k_{A} \cdot k_{b T}$, 


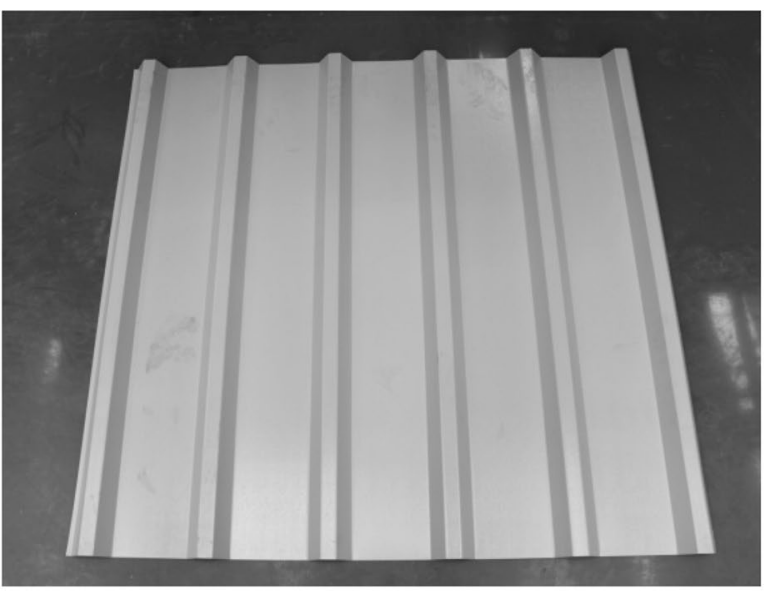

(a)

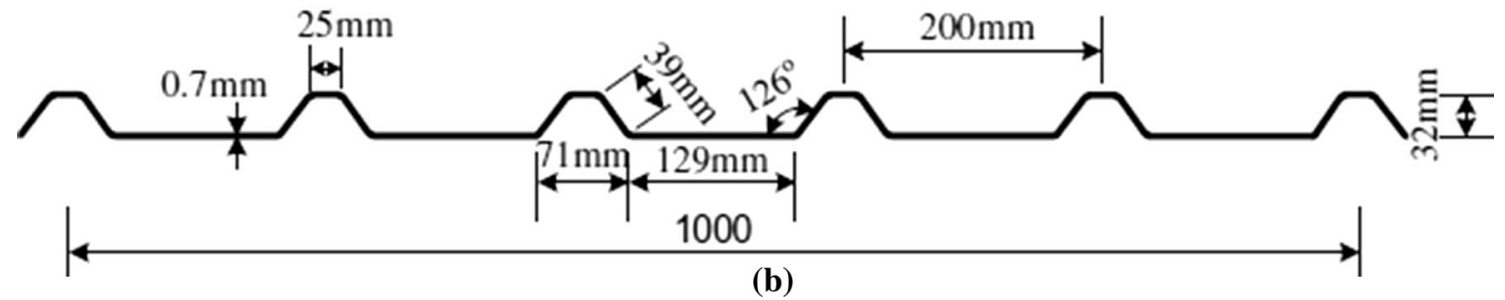

Fig. 3 Configurations of sheeting. a Picture of the sheeting. b Geometric dimensions of sheeting. (Ref. to Zhao et al. (2014))

Table 1 Geometric dimensions of $\boldsymbol{\Sigma}$-sections

\begin{tabular}{lllllll}
\hline Specimen & $W(\mathrm{~mm})$ & $F(\mathrm{~mm})$ & $L(\mathrm{~mm})$ & $O(\mathrm{~mm})$ & $S(\mathrm{~mm})$ & $t(\mathrm{~mm})$ \\
\hline$\sum 20012$ & 200 & 62.5 & 20 & 45 & 16 & 1.2 \\
$\sum 20016$ & 200 & 62.5 & 20 & 45 & 16 & 1.6 \\
$\sum 20025$ & 200 & 62.5 & 20 & 45 & 16 & 2.5 \\
$\sum 24015$ & 240 & 62.5 & 20 & 45 & 16 & 1.5 \\
$\sum 24023$ & 240 & 62.5 & 20 & 45 & 16 & 2.3 \\
$\sum 24030$ & 240 & 62.5 & 20 & 45 & 16 & 3.0 \\
$\sum 30018$ & 300 & 75 & 20 & 60 & 16 & 1.8 \\
$\sum 30025$ & 300 & 75 & 20 & 60 & 16 & 2.5 \\
$\sum 30030$ & 300 & 75 & 20 & 60 & 16 & 3.0 \\
\hline
\end{tabular}

Table 2 Geometric dimensions of C- and Z-sections

\begin{tabular}{lllll}
\hline Specimen & $W(\mathrm{~mm})$ & $F(\mathrm{~mm})$ & $L(\mathrm{~mm})$ & $t(\mathrm{~mm})$ \\
\hline C20012 & 200 & 62.5 & 20 & 1.2 \\
C24023 & 240 & 62.5 & 20 & 2.3 \\
C30030 & 300 & 75 & 20 & 3.0 \\
Z14614 & 145 & 62.5 & 20 & 1.4 \\
Z14618 & 145 & 62.5 & 20 & 1.8 \\
Z20617 & 200 & 65 & 20 & 1.7 \\
Z30720 & 300 & 75 & 20 & 2.0 \\
\hline
\end{tabular}

where $k_{b a}=\left(\frac{b_{a}}{100}\right)^{2}$ if $b_{a}<125 \mathrm{~mm} ; k_{t}=\left(\frac{t_{n o m}}{0.75}\right)^{1.5}$ if $t_{\text {nom }}<0.75 \mathrm{~mm} ; k_{b R}=\frac{185}{b_{R}}$ if $b_{R}>185 \mathrm{~mm} ; k_{A}=1.0$ when the sheet thickness less than $0.75 \mathrm{~mm} ; k_{b T}=\sqrt{\frac{b_{T, \max }}{b_{T}}}$ if $b_{T}>b_{T, \max }$ otherwise $k_{b T}=1 ; b_{a}$ is the width of the purlin flange; $t_{\text {nom }}$ is the thickness of the sheeting; $b_{R}$ is the corrugation width; $b_{T}$ is the width of the sheeting flange through which it is fastened to the purlin; $b_{T, \max }$ is given in Table 10.3 EN 1993-1-3; $C_{100}$ is a rotation coefficient, representing the value of $C_{D, A}$ if $b_{a}=100 \mathrm{~mm}$. 


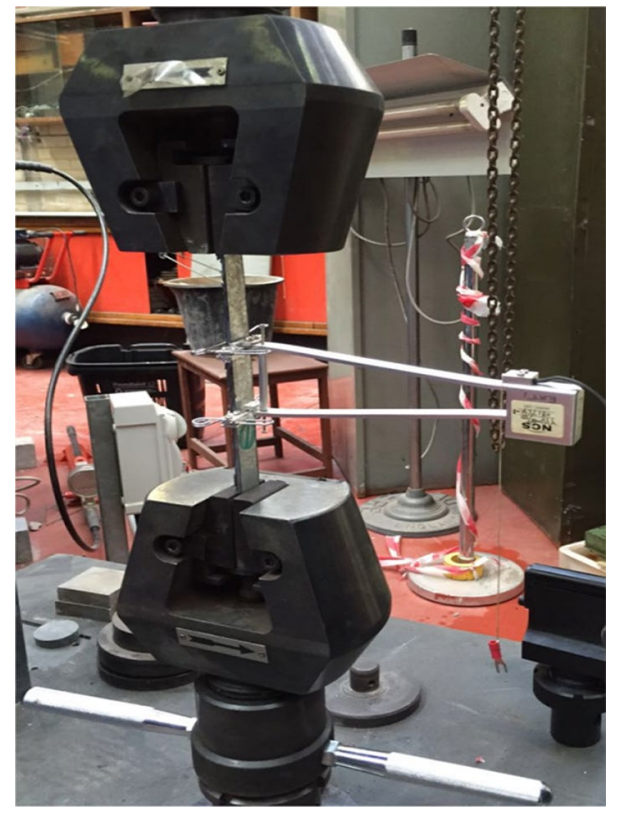

Fig. 4 Tensile test setup

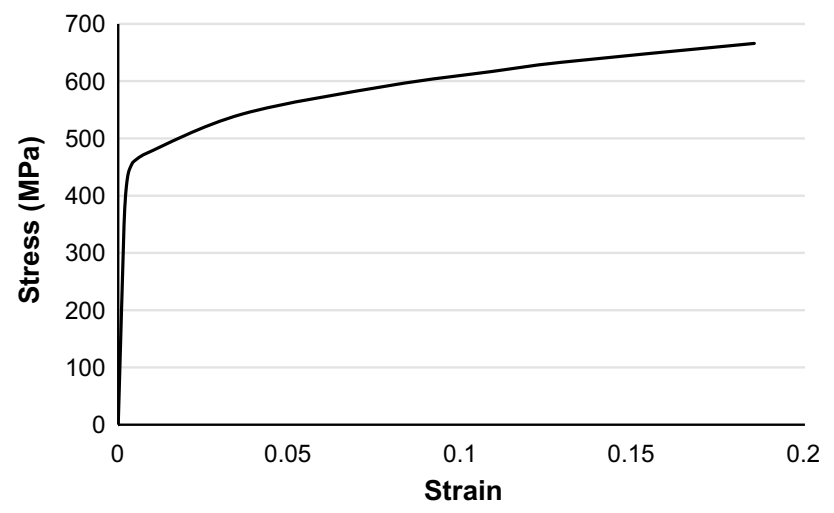

Fig. 5 Stress-strain curve of the material

\section{Numerical Approach}

\subsection{Modeling Process}

Numerical method is introduced herein using the commercial FE package ABAQUS (Abaqus-6.13 2013) to model the laboratory tests. The purlin and sheeting are modeled by 4 -node 3D deformable shell elements S4R. The fastener is modeled by 4-node 3D rigid shell elements R3D4 as it is considered strong enough and without any deformations. Depending on the geometries of the purlin and the sheet, different mesh densities are chosen through an extensive trial-and-error process. The most satisfactory result is achieved when using the following discretization pattern: the basic mesh size is $13 \mathrm{~mm}$ and a refined mesh

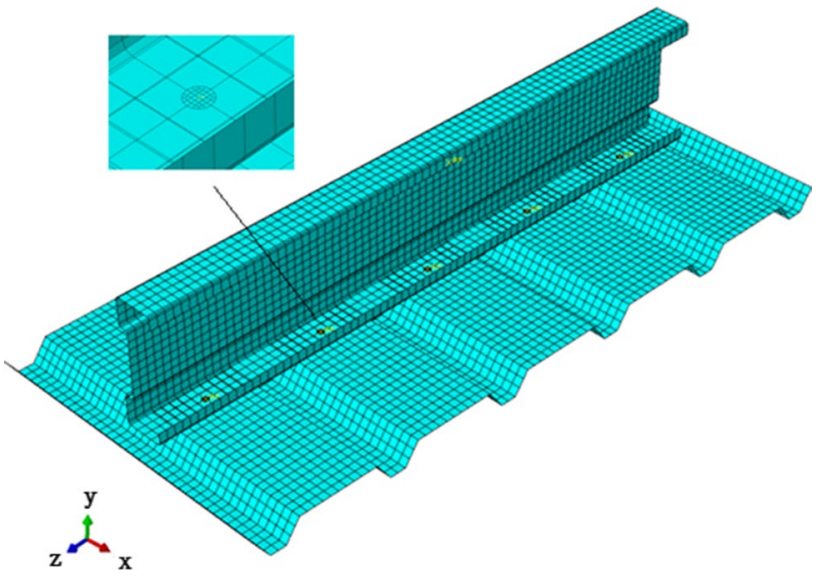

Fig. 6 Meshed model

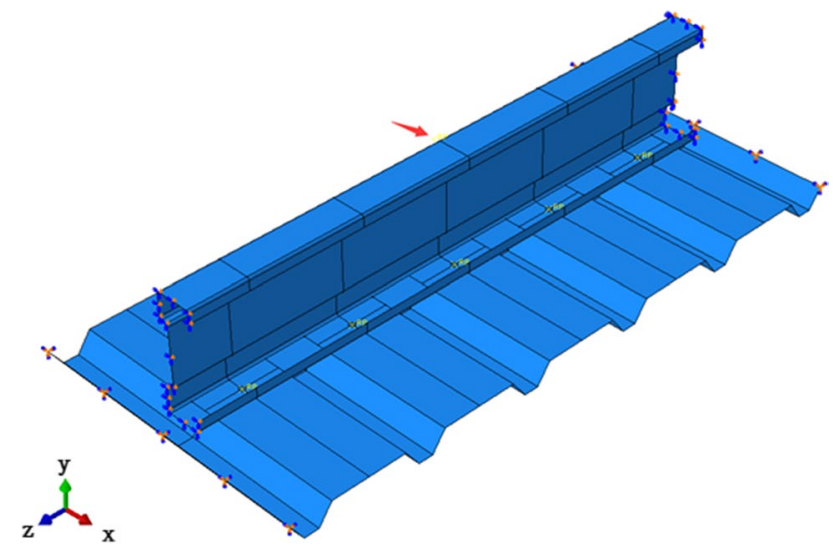

Fig. 7 Boundary conditions

of $1 \mathrm{~mm}$ is applied around the bolt hole. An example of the mesh pattern is shown in Fig. 6. The interaction between the shell and bolt is "tie" contact and the "hard contact" condition is applied between purlin and the sheeting to remove over-closure between surfaces. The sheeting is simply supported and the purlin is restrained in the longitudinal direction ( $z$ axis) to prevent overall movement. A point load is applied at the mid-span of the purlin by creating a reference point located at the flange-to-web junction line or the flange-to-lip junction line to represent the uplift or downward case (as shown in Fig. 7). A nonlinear incremental-iterative, Full-Newton solution is adopted in the analysis. The material property for the purlin element is simulated by a multi-linear stress-strain curve based on the true stress-strain curve from the coupon tests (see Fig. 5); for the sheeting element, the material property is given by a bilinear stress-strain curve with nominal yield strength of $235 \mathrm{MPa}$. 


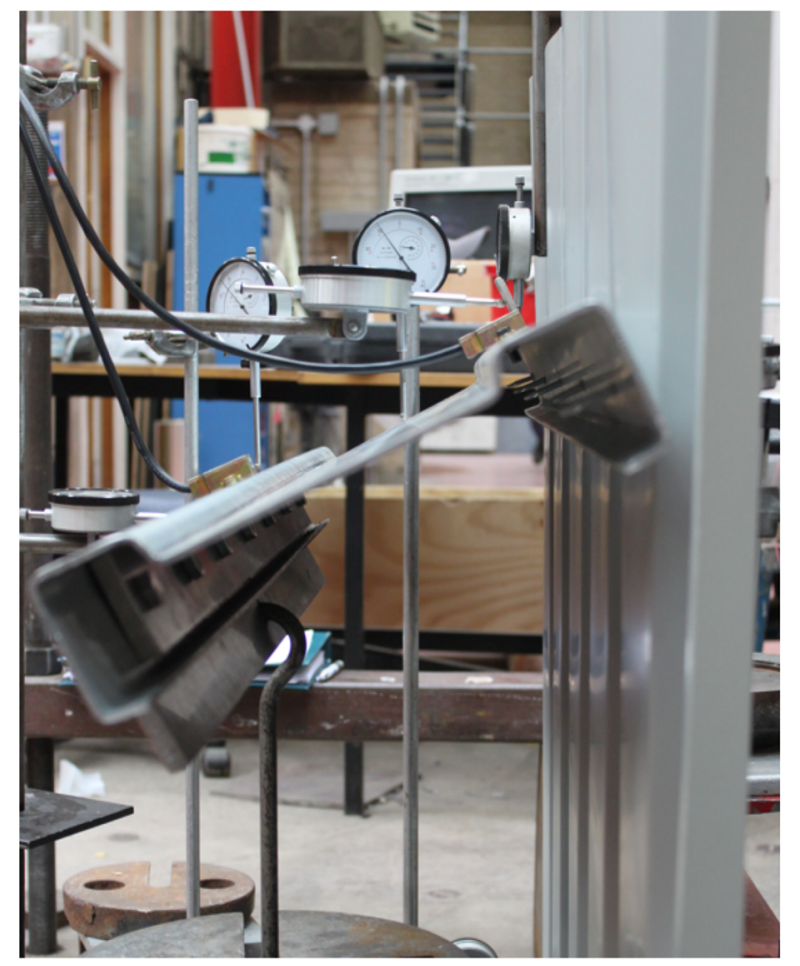

$\mathrm{U}, \mathrm{U} 1$

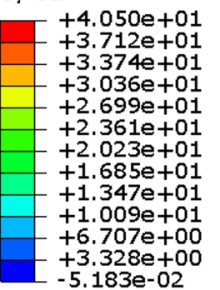

$-5.183 e-02$

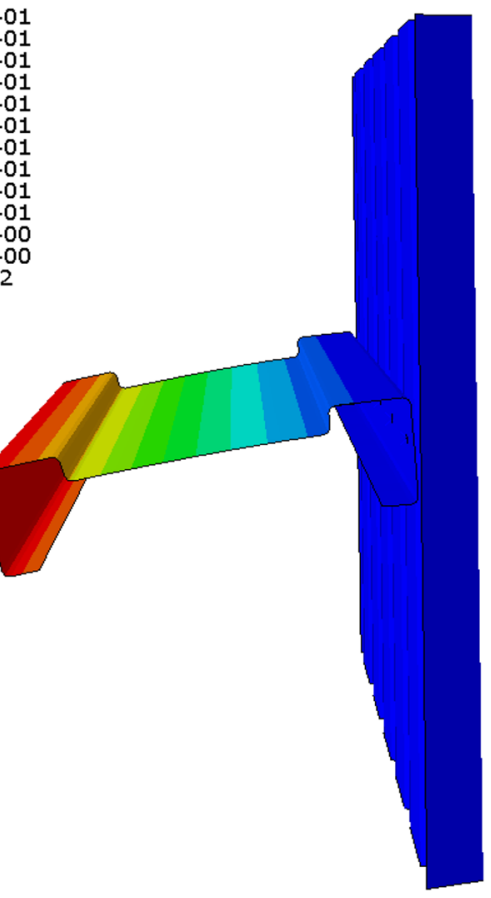

(a)
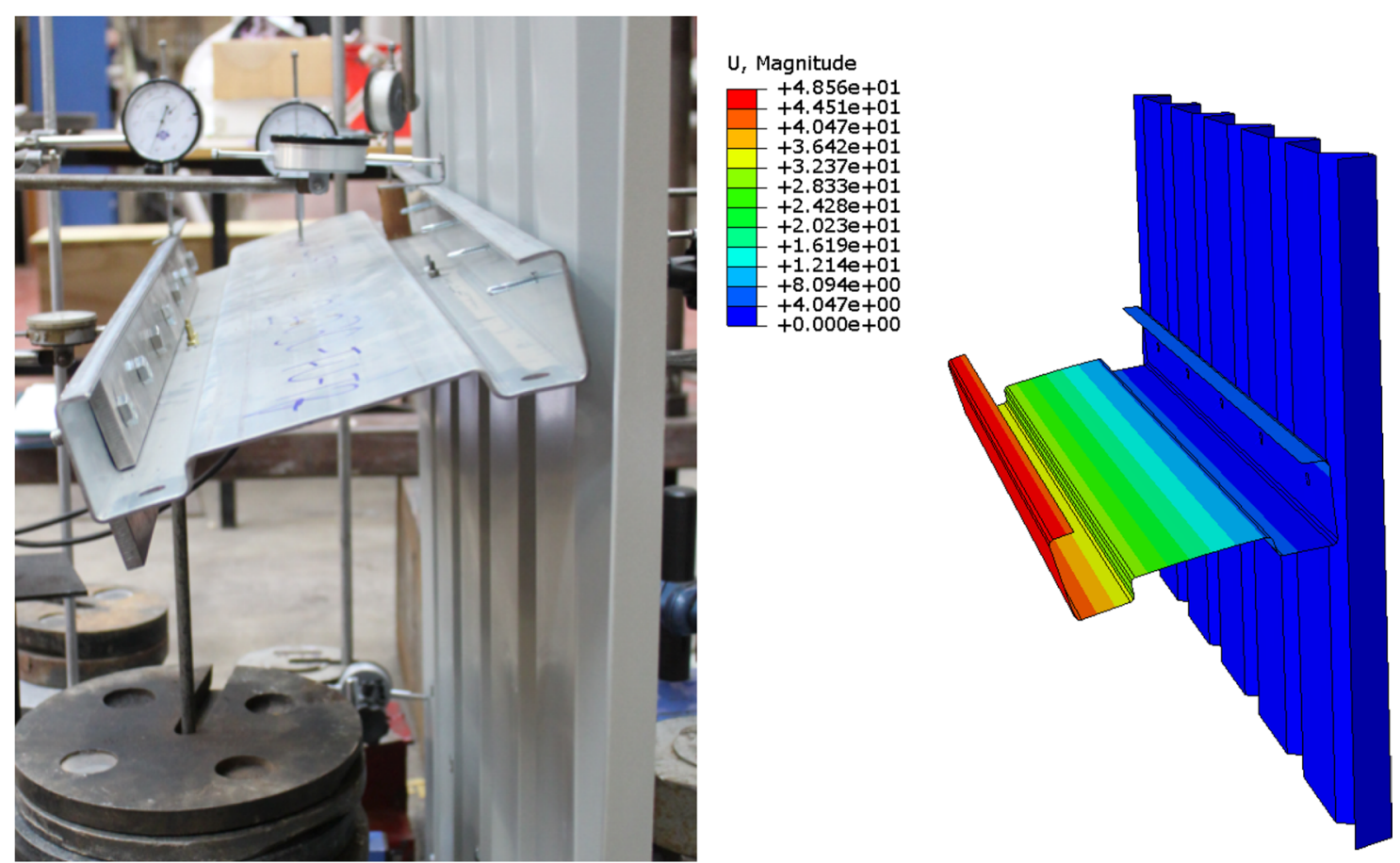

(b)

Fig. 8 Structural deformation of the purlin. a Under uplift load. b Under downward load 

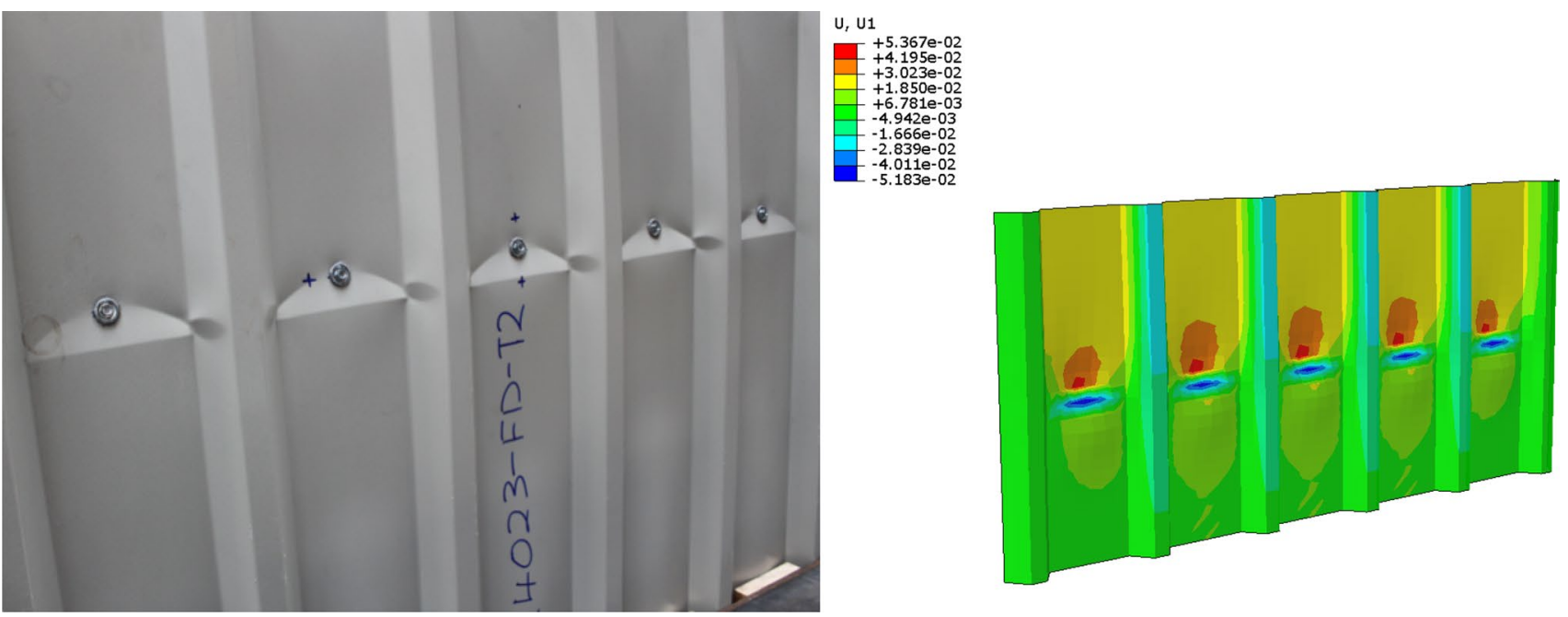

Fig. 9 Deformation of the sheeting

\subsection{Results and Discussions}

The structural deformation of the purlin and the sheeting in the FE model is shown in Figs. 8 and 9 respectively. It can be seen that with the angle of rotation increases, the maximum deformation on the sheeting occurs around the connection point on the trough region.

The comparison of the moment-rotation curves from experimental and numerical results is shown in Fig. 10. Rotational stiffness obtained from the FEM $C_{F E M}$ is compared with the analytical calculations specified in EC3 $\left(C_{D A}^{A}\right)$ and the rotational stiffness from the laboratory test $C_{\text {Test }}$, as listed in Table 3. The results are represented by moment-rotation relationships and the $C_{D, A}$ value in FEM is determined when the applied load causes the free edge of the purlin to exhibit a lateral displacement equals to $1 / 10$ of the web depth, which according to the measurement method in the test (Zhao et al. 2014).

According to Fig. 10, a good agreement can be found between the FEM and the test results, implying that the numerical model is valid. Table 3 demonstrates that the average ratio of the predicted rotational stiffness between the numerical model and the test is 1.09 , with a standard deviation of 0.07 , whereas the average analytical-to-test ratio is 1.03 , with a standard deviation of 0.42 . It can be concluded that FEM has a better capability in predicting rotational stiffness than the current analytical expressions. One reason for the discrepancy between FEM and test result is the negligence of the washer in the numerical model, which was used in the test to avoid local failure by reducing concentration stress around the bolt hole. And another reason lead to a overestimating of the rotational stiffness (by 9\%) in FEM is because in the test, the total rotation angle of the specimen includes the rotation angle caused by the localized deformation of the sheet, the rotation angle because of the separation between the sheeting and the purlin at the connected point and the rotation angle due to the bending of purlin flange, but in the FEM, the effects of the screw-toshell separation was eliminated by using rigid plates to simulate the fastener and applying non-separable "tie" connection between the purlin and the sheeting.

\subsection{Parametric Studies}

A series of parametric studies are conducted to investigate the influence of the fastener spacing and sheeting thickness on the rotational stiffness, and only one variable is changed at a time during the analysis.

\subsubsection{Fastener Spacing}

In the following figures, the $y$-axis represents the rotational stiffness and the $x$-axis represents the ratio between fastener spacing (e) and corrugation width $b_{R}\left(b_{R}=200 \mathrm{~mm}\right.$ according to the test). The fastener used in the models is rigid shell elements with the diameter of $5.5 \mathrm{~mm}$.

\subsubsection{Sheeting Thickness}

The corrugated sheeting with three thicknesses $\left(t_{s}\right), 0.7,1.0$ and $1.5 \mathrm{~mm}$, are analyzed herein.

\subsubsection{Purlin Web Depth, Flange Width and Shell Thickness}

The effect of varying web depth, flange width and shell thickness on the rotational stiffness of the purlin-sheeting connection is demonstrated in the following figures. 

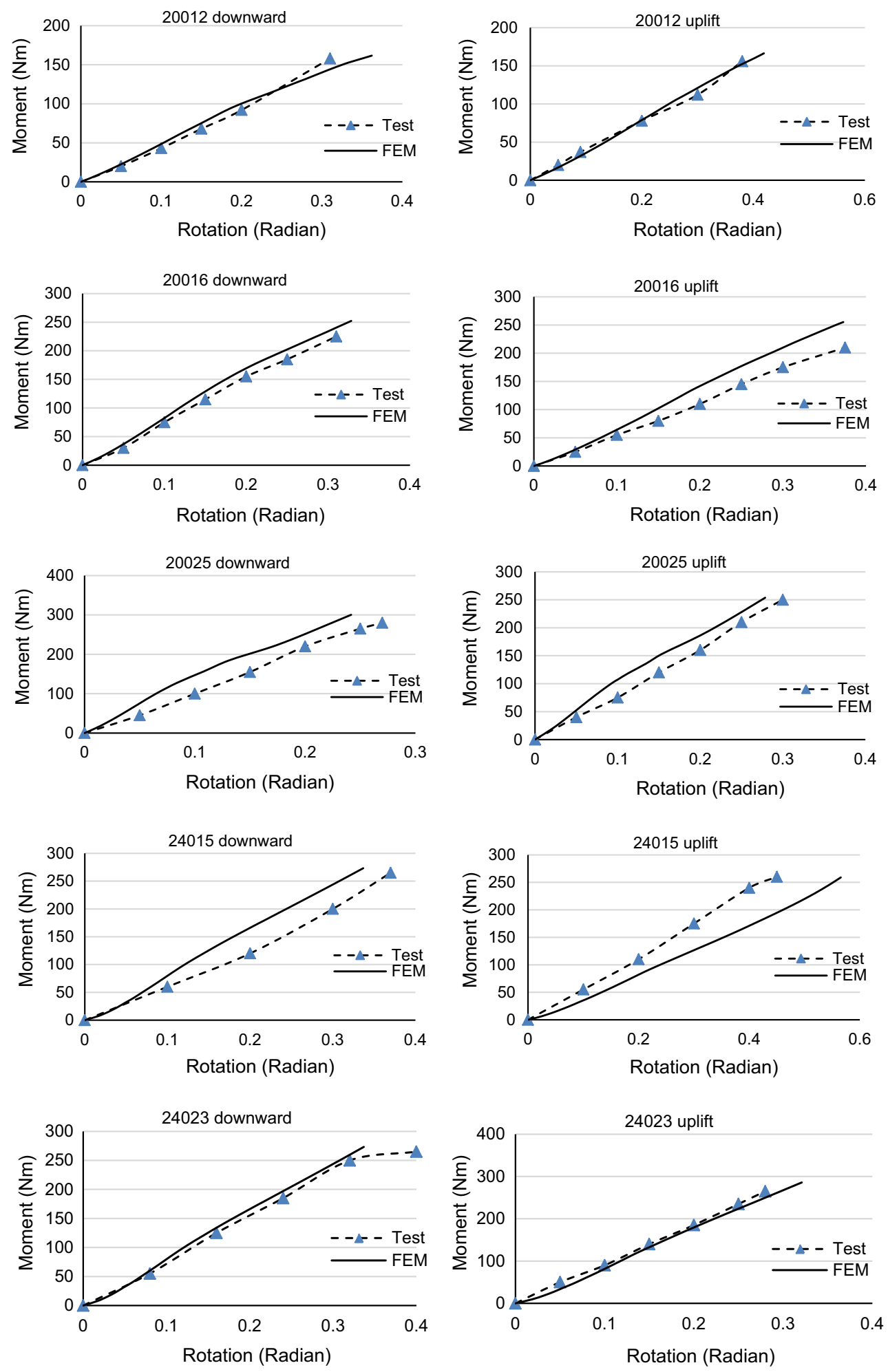

Fig. 10 Moment to rotation curves

Figure 11 shows that as the fastener spacing increases, the rotational stiffness decreases as expected. The FEM results show good accordance with the test results. The mean value in FEM drops by 36 and 33\% for downward loading case and uplift loading cases, respectively, when increasing fastener spacing from $1.0 b_{R}$ to $2.0 b_{R}$. 

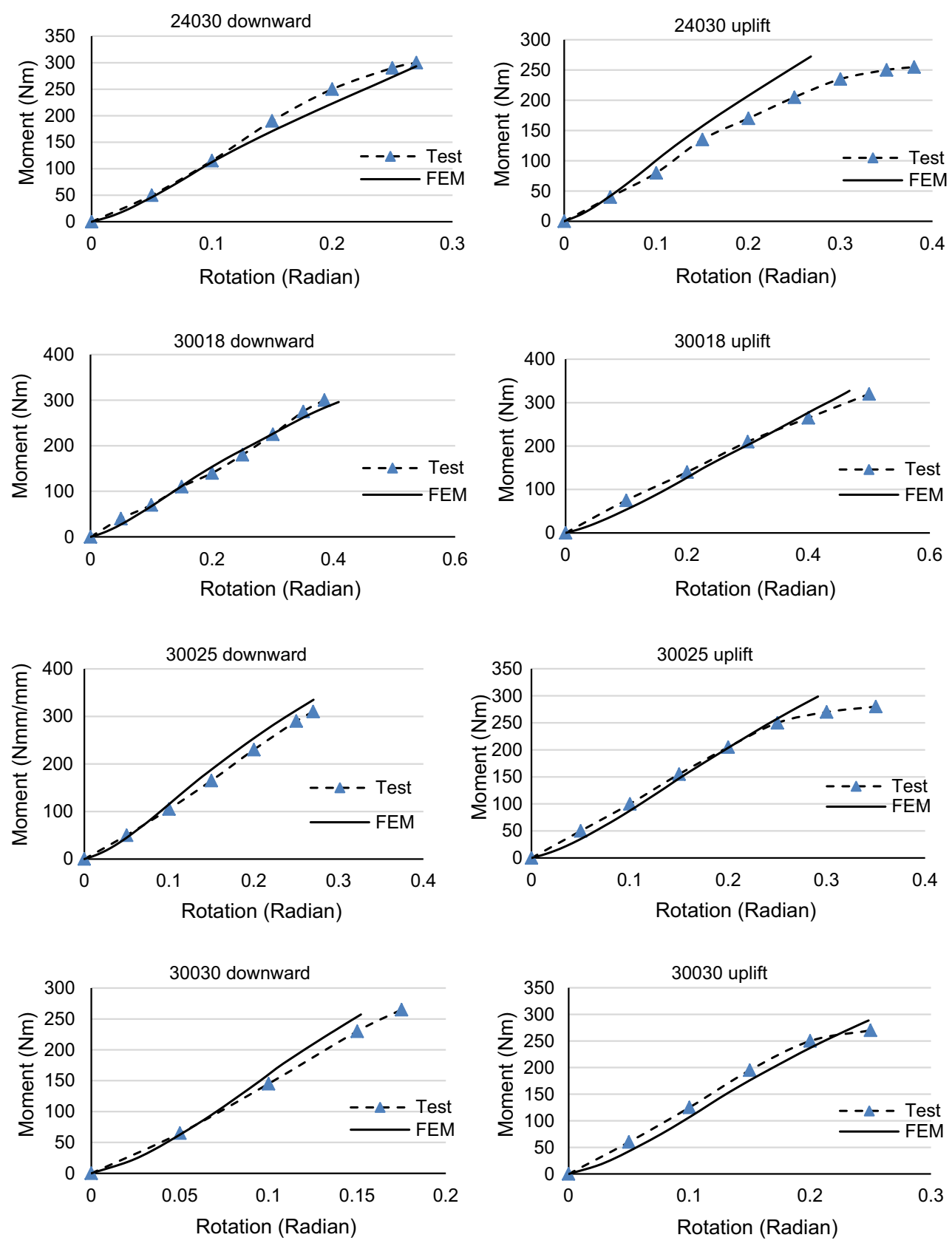

Fig. 10 (continued)

It is found in Fig. 12 that the sheet thickness has a significant effect on the rotation behavior of the sigma purlin-corrugated sheeting system. Rotational stiffness increases for the 200 series purlin with increasing sheet thickness from $0.7 \mathrm{~mm}$ to $1.2 \mathrm{~mm}$. The EC3 and FEM show an increase of 71 and $87 \%$ in the rotational stiffness under downward load when the thickness increases from $0.7 \mathrm{~mm}$ to $1.0 \mathrm{~mm}$, and an increase of 31 and $43 \%$ when the thickness increases from $1.0 \mathrm{~mm}$ to $1.2 \mathrm{~mm}$, respectively. A similar trend can be identified for the 200 series purlin under uplift load, with the corresponding values being 71 and $31 \%$ for EC3 method, and 75 and $35 \%$ for FEM.

The comparison of the rotational stiffness curves of the connections for the varying web depth is demonstrated in Fig. 13. It indicates that with increasing web depth from 200 to $225 \mathrm{~mm}$, the change of rotational stiffness under downward load is limited. Further increase from 225 to $240 \mathrm{~mm}$ has resulted in $6.8 \%$ increase in the rotational stiffness. For the connection under uplift load, the effect of web depth on the rotational stiffness is not obvious. It shows in the Fig. 14 that the rotational stiffness increases remarkably 
Table 3 Comparison of $C_{D, A}$ results

\begin{tabular}{|c|c|c|c|c|c|c|c|}
\hline \multirow[t]{2}{*}{ Specimen } & \multicolumn{4}{|l|}{ FEM } & \multicolumn{3}{|c|}{ Comparison } \\
\hline & Load (N) & $\theta(\mathrm{rad})$ & $\begin{array}{l}C_{F E M} \\
(\mathrm{Nm} / \mathrm{m} / \\
\mathrm{rad})\end{array}$ & $C_{\text {Test }}(\mathrm{Nm} / \mathrm{m} / \mathrm{rad})$ & $C_{F E M} C_{\text {Test }}$ & $C_{D, A}^{A}(\mathrm{Nm} / \mathrm{m} / \mathrm{rad})$ & $C_{D, A}^{A} C_{T e s t}$ \\
\hline$\sum 20012 \mathrm{D}$ & 150 & 0.065 & 573 & 502 & 1.14 & 970 & 1.93 \\
\hline$\sum 20012 U$ & 125 & 0.073 & 450 & 394 & 1.14 & 470 & 1.19 \\
\hline$\sum 20016 \mathrm{D}$ & 256 & 0.066 & 756 & 691 & 1.09 & 970 & 1.40 \\
\hline$\sum 20016 U$ & 238 & 0.077 & 638 & 622 & 1.03 & 470 & 0.76 \\
\hline$\sum 20025 \mathrm{D}$ & 606 & 0.079 & 1049 & 1024 & 1.02 & 970 & 0.95 \\
\hline$\sum 20025 U$ & 606 & 0.089 & 943 & 895 & 1.05 & 470 & 0.53 \\
\hline$\sum 24015 \mathrm{D}$ & 230 & 0.060 & 760 & 696 & 1.09 & 970 & 1.39 \\
\hline$\sum 24015 \mathrm{U}$ & 148 & 0.066 & 582 & 593 & 0.98 & 470 & 0.79 \\
\hline$\sum 24023 \mathrm{D}$ & 484 & 0.081 & 980 & 1009 & 0.97 & 970 & 0.96 \\
\hline$\sum 24023 \mathrm{U}$ & 438 & 0.085 & 876 & 848 & 1.03 & 470 & 0.55 \\
\hline$\sum 24030 \mathrm{D}$ & 641 & 0.091 & 1156 & 1047 & 1.10 & 970 & 0.93 \\
\hline$\sum 24030 \mathrm{U}$ & 641 & 0.099 & 1057 & 909 & 1.16 & 470 & 0.52 \\
\hline$\sum 30018 \mathrm{D}$ & 202 & 0.074 & 943 & 753 & 1.25 & 1397 & 1.86 \\
\hline$\sum 30018 \mathrm{U}$ & 150 & 0.073 & 785 & 735 & 1.07 & 677 & 0.92 \\
\hline$\sum 30025 \mathrm{D}$ & 338 & 0.080 & 1181 & 1078 & 1.10 & 1397 & 1.30 \\
\hline$\sum 30025 \mathrm{U}$ & 275 & 0.080 & 1050 & 921 & 1.14 & 677 & 0.74 \\
\hline$\sum 30030 \mathrm{D}$ & 430 & 0.085 & 1292 & 1191 & 1.08 & 1397 & 1.17 \\
\hline$\sum 30030 \mathrm{U}$ & 353 & 0.083 & 1171 & 977 & 1.20 & 677 & 0.69 \\
\hline Mean & & & & & 1.09 & & 1.03 \\
\hline SD & & & & & 0.07 & & 0.42 \\
\hline
\end{tabular}

$C_{F E M}$ is the rotational stiffness obtained from FEM; $C_{\text {Test }}$ is the rotational stiffness obtained from the laboratory tests; $C_{D, A}^{A}$ is the analytical rotational stiffness achieved by EC3; $D$ represents the downward load case and $\mathrm{U}$ represents the uplift load scenario with increasing section thickness for both downward and uplift load. For the connections with downward load, with the increase in purlin shell thickness from 1.5 to $1.8,2.3$ and $3.0 \mathrm{~mm}$ has exhibited 15, 29 and 52\% increase, respectively, in rotational stiffness. The same trend can be noted for the connections with uplift load, with increasing thickness from 1.5 to $1.8,2.3$ and $3.0 \mathrm{~mm}$ has resulted in 21,51 and $82 \%$ increase in the rotational stiffness. From Fig. 15, for the downward load scenario it can be seen that there is $\mathbf{5 2}$ and $27 \%$ increase in rotational stiffness when flange width increase from 50 to 62.5 and from 62.5 to $75 \mathrm{~mm}$. For the uplift load scenario, there is 24 and $14 \%$ increase in the rotational stiffness with increasing flange width. The similar trend can be observed from codified approach (EC3). For the downward load case, the rotational stiffness of the connection with $62.5 \mathrm{~mm}$ flange width is $52 \%$ more than the connection with $50 \mathrm{~mm}$ width and the connection with $75 \mathrm{~mm}$ width is $48 \%$ more than $62.5 \mathrm{~mm}$ width. For the uplift load case, the increase in the rotational stiffness by 56 and $44 \%$ with respect to the increase in flange width from 50 to 62.5 and from 62.5 to $75 \mathrm{~mm}$.

Since the analytical method does not consider factors such as the thickness and the overall depth of the purlin, a modification method is hence presented herein to improve the accuracy of the codified method. It needs to be noted that as the influence caused by web depth is insignificant on the rotational stiffness, the effect is discarded in the following modification process.

\section{Modification Approach}

The experimental and numerical outcomes show that the codified design approach in EC3 is less accurate for predicting the rotational stiffness as it neglects the effect of the purlin thickness and underestimate the effect of flange width. Therefore, a compensation coefficient $\varphi(t, F)$, is introduced herein to modify the EC3 approach, given by Eq. (4). The relationship between the modified analytical value $C_{D, A}^{M}$ and the EC3 codified value $C_{D, A}^{A}$ is given by Eq. (5):

$\varphi(t, F)=\beta_{t} \beta_{F}$,

$C_{D, A}^{M}=\varphi(t, F) C_{D, A}^{A}$,

where $\beta_{t}$ and $\beta_{f}$ are the correction coefficients for shell thickness and flange width respectively; $C_{D, A}^{M}$ is the modified analytical value. 

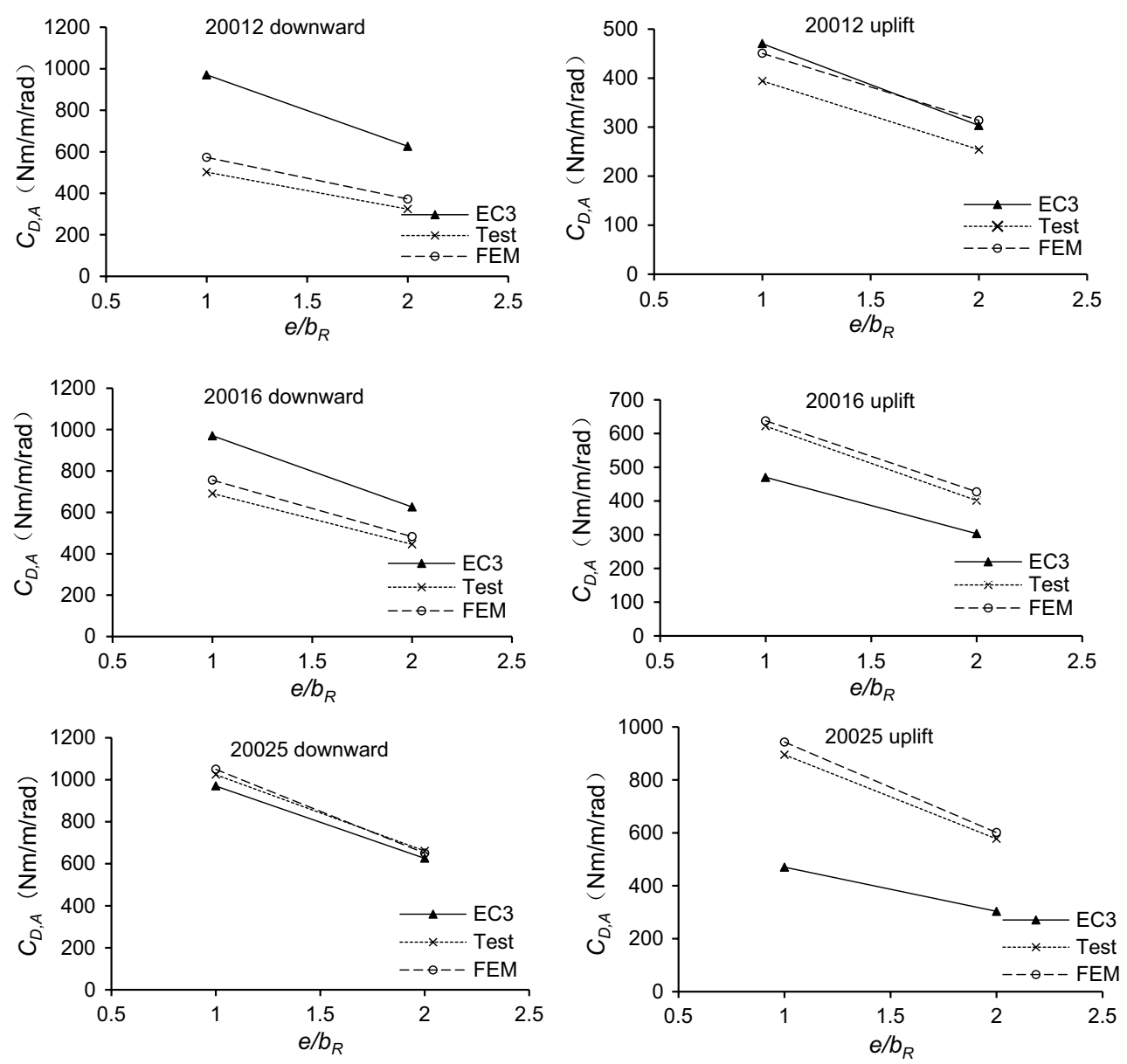

Fig. 11 The effect of fastener spacing

The design formula for $\beta_{F}$ is derived from the parametric study and the formulae for $\beta_{t}$ is obtained based on the regression analysis. In the analysis, the purlin thickness $(t)$ is determined as the main variables affecting stiffness of purlin system. By curved relationship between ( $t$ ) and dependent variable $(y)$, the nonlinear expectation function is assumed to be parabola (see Figs. 16, 17):

$y=a+b t+c t^{2}$

The expressions of $\beta_{t}$ for downward and uplift load can be obtained using data analysis software ORIGIN8.0, as shown in Eqs. (8)-(9). In order to improve the accuracy of the analysis, the equations are employed when determination coefficients are over 0.98 in the regression analysis.

$\beta_{F}=\frac{10}{F-20}$,

For downward load,

$\beta_{t, d}=-0.4 t^{2}+3.1 t-0.6$

and for uplift load,

$\beta_{t, u}=-0.7 t^{2}+6.1 t-2.2$,

where $t$ is the thickness of section and $F$ is the width of flange.

The comparison of rotational stiffness $\left(C_{D, A}\right)$ between modified analytical method and other approaches is shown in the following figures.

As shown in Fig. 18, in contrast to test results, predictions obtained by the current specification (EC3) generally overestimate the rotational stiffness of the purlin-to-sheet connection under gravity load. On the contrary, when uplift load is applied on the sheet, conservative results are obtained from the analytical approach (EC3). Meanwhile, the modified method shows better agreement with the test results, with the average ratio being 1.10 and 1.00 , and the standard deviation being 0.07 and 0.08 for the download and uplift scenario, respectively (see Fig. 19).

In order to further examine the validity of the modified method, more purlin-sheeting models with $\mathrm{C}$ - and Z-sections are analyzed. The comparison is listed in Table 4. 

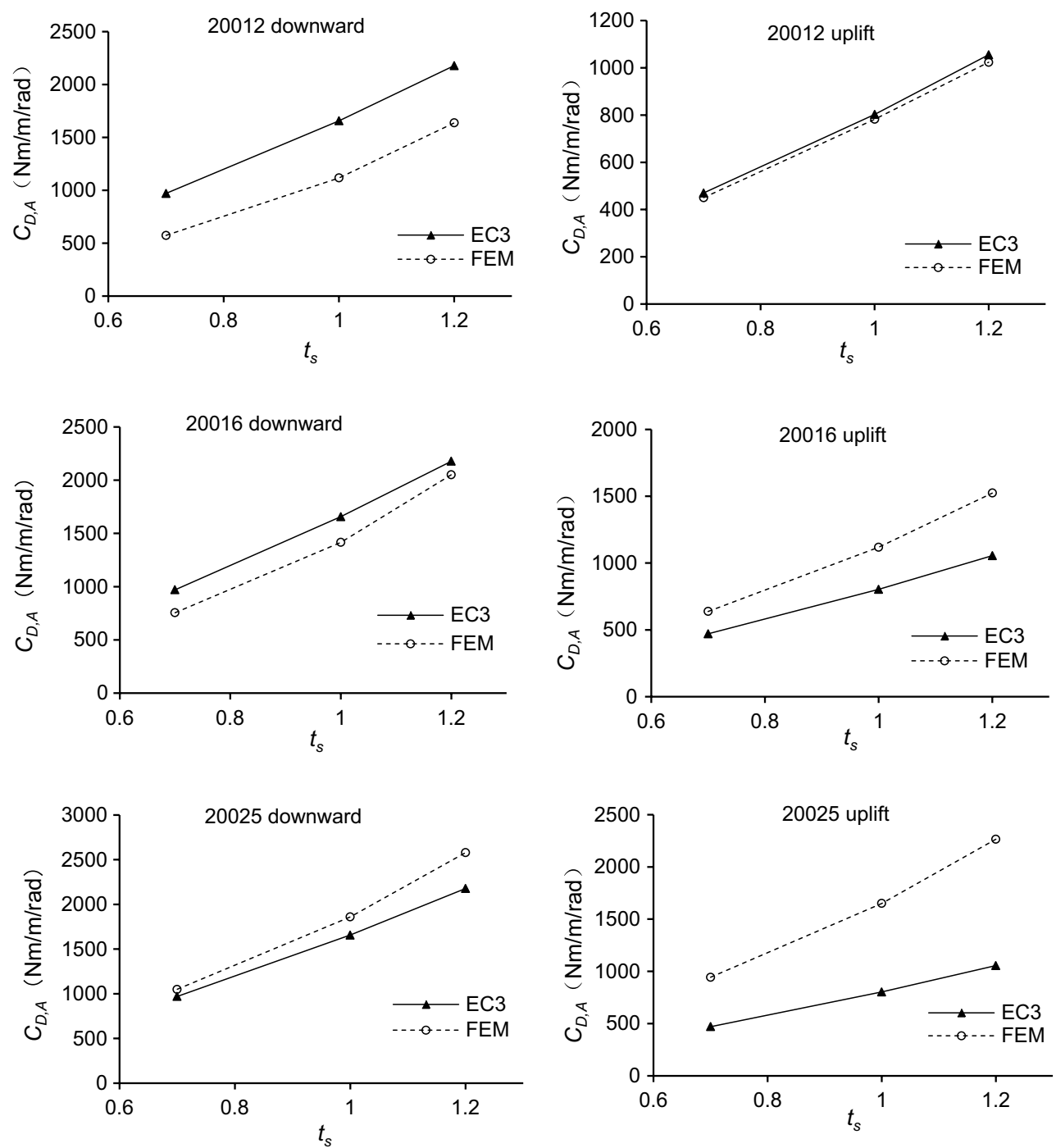

Fig. 12 The effect of sheeting thickness
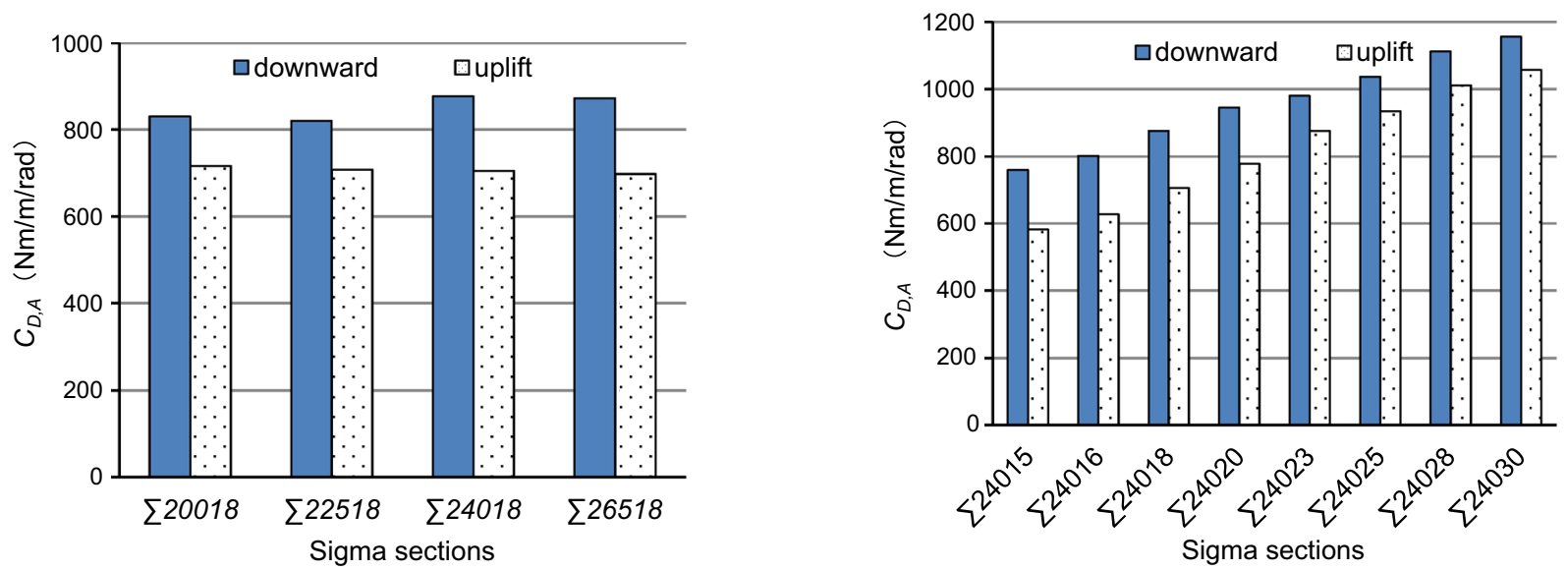

Fig. $13 C_{D, A}$ with different web depths

Fig. $14 C_{D A}$ with different shell thickness 
Fig. $15 C_{D, A}$ with different flange widths
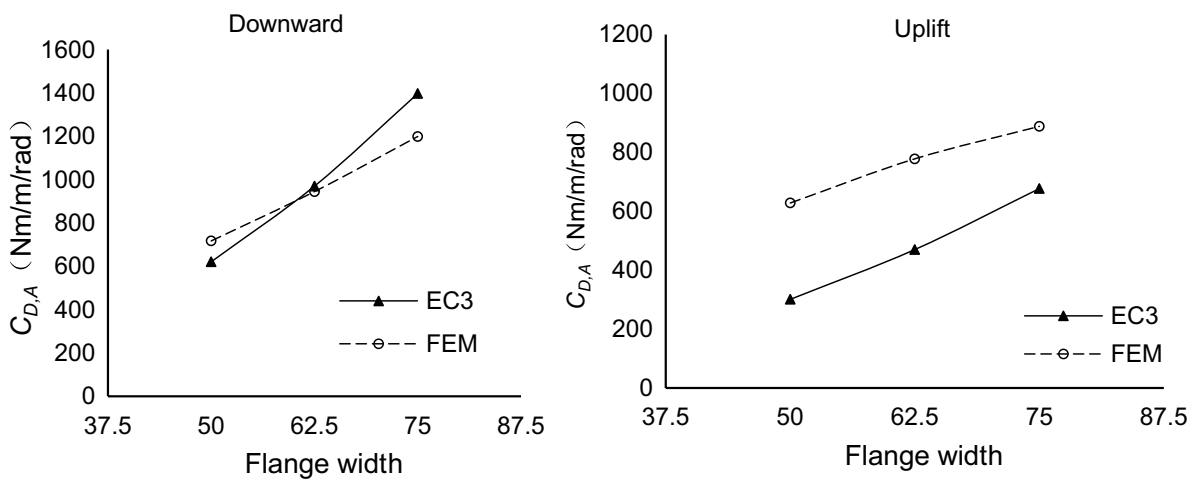

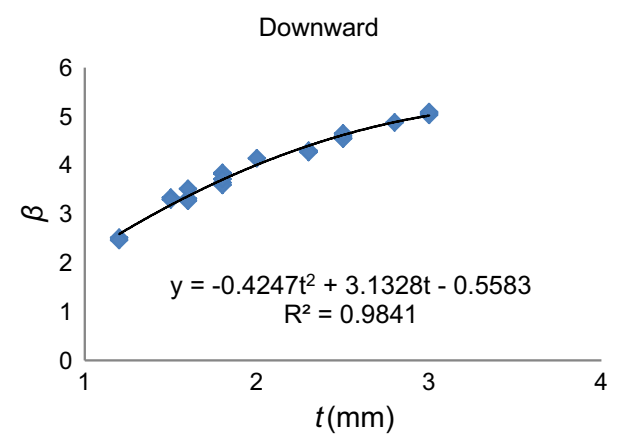

Fig. $16 \beta-t$ relationship under downward load

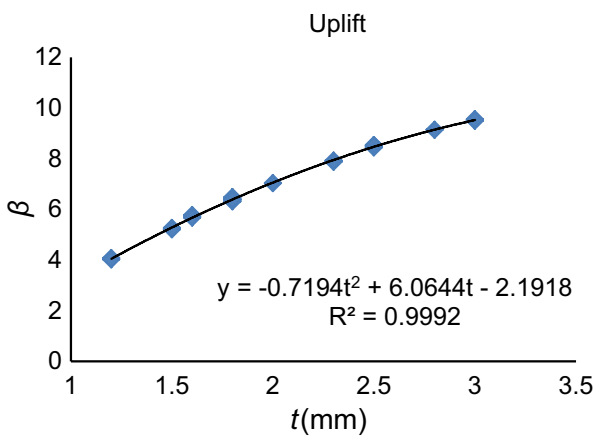

Fig. $17 \beta-\mathrm{t}$ relationship under uplift load

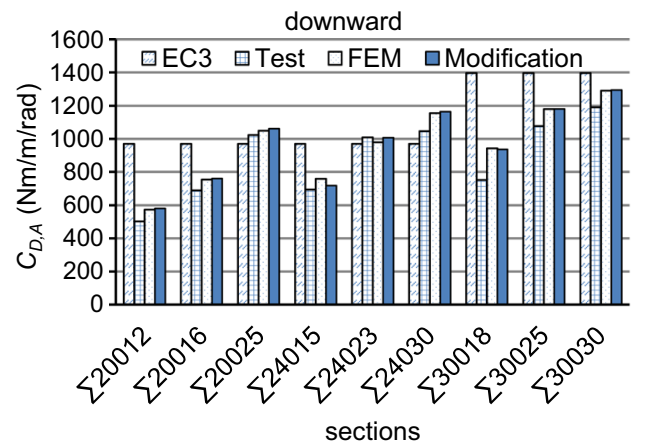

It shows that the test results of $\mathrm{C}$ - and Z-section purlins are also in good agreement with the modified analytical method. The average value of $C_{D, A}^{M} / C_{\text {Test }}$ shows a very slightly better agreement than $C_{D, A}^{A} / C_{\text {Test }}(1.00-1.01)$, and the former also shows more stability than latter, with the standard deviations being 0.05 and 0.33 , respectively.

\section{Conclusions}

In the current paper, the investigation on rotational stiffness in the purlin-sheeting system under both downward and uplift load scenarios has been presented. Based on the comparison between the test results and the analytical values predicted by current design code, it is found that the purlin thickness and flange width have a significant impact on the rotational stiffness in the purlin-sheeting system and therefore modification of the current design method is required. In order to improve the accuracy of codified method, a series of numerical and parametric studies are carried out involving $\boldsymbol{\Sigma}$-, C- and Z-sections, and the following conclusions can be drawn based on the studies.

The purlin thickness has a significant effect on the rotation behavior of the purlin-corrugated sheeting system whereas the effect of increasing web depths is negligible. It shows that the rotational stiffness increases remarkably

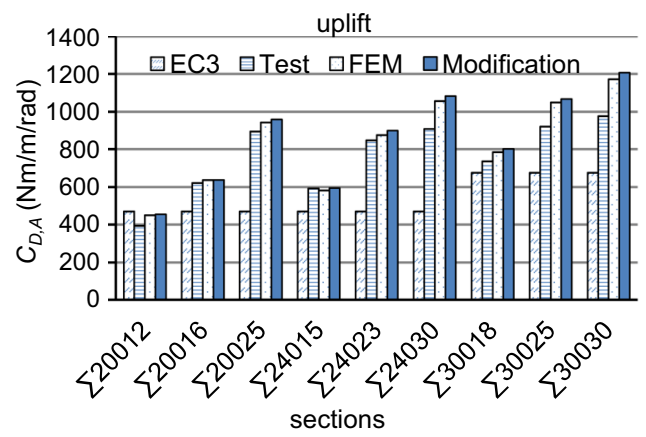

Fig. 18 Rotational stiffness $C_{D, A}$ with downward and uplift load 

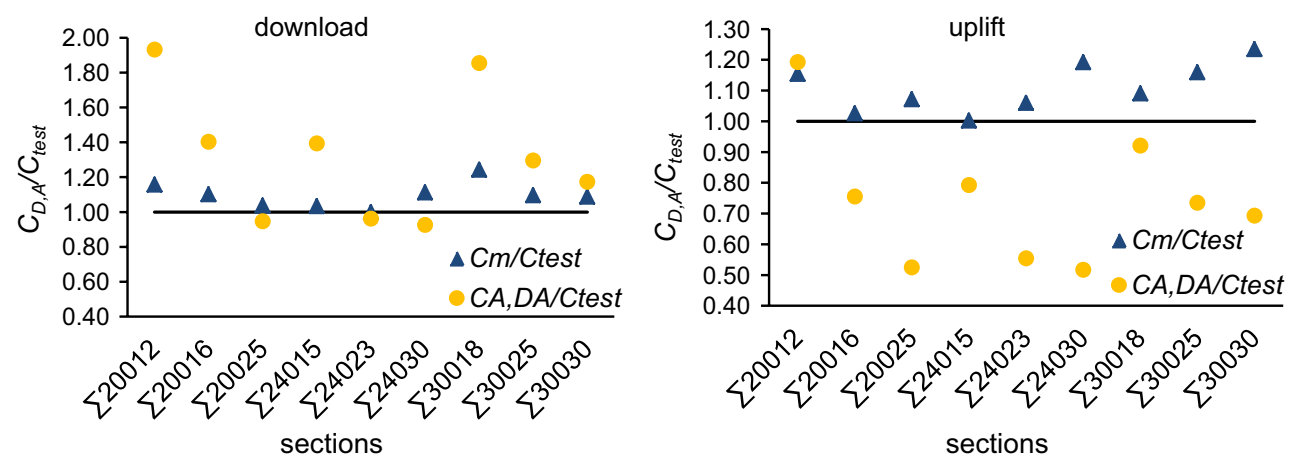

Fig. 19 Results comparison of $C_{D, A}$

Table 4 Comparison of $\mathrm{C}_{\mathrm{D}, \mathrm{A}}$ with $\mathrm{C}$ - and $\mathrm{Z}$-section purlins

\begin{tabular}{llllcccc}
\hline Specimen & $\beta_{t}$ & $\beta_{F}$ & $C_{\text {Test }}(\mathrm{Nm} / \mathrm{m} / \mathrm{rad})$ & $C_{D, A}^{\mathrm{A}}(\mathrm{Nm} / \mathrm{m} / \mathrm{rad})$ & $\mathrm{C}_{D, A}^{\mathrm{M}}(\mathrm{Nm} / \mathrm{m} / \mathrm{rad})$ & $C_{D, A}^{A} / C_{\text {Test }} C_{D, A}^{M} / C_{\text {Test }}$ \\
\hline $\mathrm{C} 20012 \mathrm{D}$ & 2.54 & 0.24 & 579 & 970 & 581 & 1.68 & 1.00 \\
$\mathrm{C} 20012 \mathrm{U}$ & 4.12 & 0.24 & 455 & 470 & 456 & 1.03 & 1.00 \\
$\mathrm{C} 24023 \mathrm{D}$ & 4.41 & 0.24 & 986 & 970 & 1007 & 0.98 & 1.02 \\
$\mathrm{C} 24023 \mathrm{U}$ & 7.95 & 0.24 & 883 & 470 & 879 & 0.53 & 1.00 \\
$\mathrm{C} 30030 \mathrm{D}$ & 5.10 & 0.18 & 1297 & 1397 & 1295 & 1.08 & 1.00 \\
$\mathrm{C} 30030 \mathrm{U}$ & 9.53 & 0.18 & 1176 & 677 & 1173 & 0.58 & 1.00 \\
Z14614D & 2.96 & 0.24 & 762 & 970 & 675 & 1.27 & 0.89 \\
Z14614U & 4.89 & 0.24 & 512 & 470 & 541 & 0.92 & 1.06 \\
Z14618D & 3.68 & 0.24 & 820 & 970 & 841 & 1.18 & 1.03 \\
Z14618U & 6.39 & 0.24 & 730 & 470 & 707 & 0.64 & 0.97 \\
Z20617D & 3.51 & 0.22 & 876 & 1050 & 820 & 1.20 & 0.94 \\
Z20617U & 6.04 & 0.22 & 680 & 508 & 682 & 0.75 & 1.00 \\
Z30720D & 4.00 & 0.18 & 955 & 1397 & 1016 & 1.46 & 1.06 \\
Z30720U & 7.06 & 0.18 & 791 & 677 & 869 & 0.86 & 1.10 \\
Mean & & & & & & 1.01 & 1.00 \\
SD & & & & & & 0.33 & 0.05 \\
\hline
\end{tabular}

with increasing section thickness for both downward and uplift load scenarios.

The compensation coefficient that consider the influence of shell thickness $\left(\beta_{t}\right)$ and flange width $\left(\beta_{F}\right)$ on the rotational stiffness can lead to a better agreement with the test results for sigma purlins. This approach is also approved to be applicable on zed and channel purlins.

Acknowledgements The authors are grateful for the financial support of the China Postdoctoral Science Foundation (17Z102060052).

Open Access This article is distributed under the terms of the Creative Commons Attribution 4.0 International License (http://creativeco mmons.org/licenses/by/4.0/), which permits unrestricted use, distribution, and reproduction in any medium, provided you give appropriate credit to the original author(s) and the source, provide a link to the Creative Commons license, and indicate if changes were made.

\section{References}

ABAQUS-6.13. (2013). Analysis user's manual. Town of Johnston, RI: SIMULIA.

Bai, L., Wang, F., Wadee, M. A., \& Yang, J. (2017). Nonlinear mode interaction in equal-leg angle struts susceptible to cellular buckling. Proceedings of the Royal Society A, 473, 20170583.

Balazs, I., Melcher, J., \& Belica, A. (2016). Experimental investigation of torsional restraint provided to thin walled purlins by sandwich panels under uplift load. Procedia Engineering, 161, 818-824.

Bambach, M. R., \& Rasmussen, K. J. R. (2007). Behavior of self-drilling screws in light-gauge steel construction. Journal of Structural Engineering, 6, 895-898.

BSI. (2009). BS EN ISO 6892-1. Metallic materials. Tensile testing: Method of test at ambient temperature.

Chu, X.-T., Rickard, J., \& Li, L.-Y. (2005). Influence of lateral restraint on lateral-torsional buckling of cold-formed steel purlins. ThinWalled Structures, 43, 800-810.

Chung, K. F., \& Ho, H. C. (2005). Analysis and design of lapped connections between cold-formed steel Z sections. Thin-Walled Structures, 43, 1071-1090. 
Ciesielczyk, K., \& Studziński, R. (2017). Experimental and numerical investigation of stabilization of thin-walled Z-beams by sandwich panels. Journal of Constructional Steel Research, 133, 77-83.

Durr, M., Misiek, T., \& Saal, H. (2011). The torsional restraint of sandwich panels to resist the lateral torsional buckling of beams. Steel Construction, 4, 251-258.

EUROCODE. (2006). European Committee for Standardization. Eurocode3: Design of steel structures: Part 1-3: General rulessupplementary rulesfor cold-formed members and sheeting, EN 1993-1-3:2006. Brussels, Belgium, 2006.

Fiorino, L., Della Corte, G., \& Landolfo, R. (2007). Experimental tests on typical screw connections for cold-formed steel housing. Engineering Structures, 29, 1761-1773.

Gajdzicki, M., \& Goczek, J. (2015). Numerical determination of rotational restraint of cold-formed Z-purlin according to EC3. International Journal of Steel Structures, 15, 633-645.

Gao, T., \& Moen, C. D. (2012). Predicting rotational restraint provided to wall girts and roof purlins by through-fastened metal panels. Thin-Walled Structures, 61, 145-153.

Gutierrez, R., Loureiro, A., Lopez, M., \& Moreno, A. (2011). Analysis of cold-formed purlins with slotted sleeve connections. ThinWalled Structures, 49, 833-841.

Huang, X.-H., Yang, J., Liu, Q.-F., Zhu, J., Bai, L., Wang, F.-L., et al. (2018). A simplified flange-lip model for distortional buckling of cold-formed steel channel-sections with stiffened web. International Journal of Mechanical Sciences, 136, 451-459.

Huang, X., \& Zhu, J. (2016). A stiffened-plate buckling model for calculating critical stress of distortional buckling of CFS columns. International Journal of Mechanical Sciences, 119, 237-242.

Katnam, K. B., Van Impe, R., Lagae, G., \& De Strycker, M. (2007). A theoretical numerical study of the rotational restraint in coldformed steel single skin purlin-sheeting systems. Computers \& Structures, 85, 1185-1193.

Kim, J., Yoon, J. C., \& Kang, B. S. (2007). Finite element analysis and modeling of structure with bolted joints. Applied Mathematical Modelling, 31, 895-911.

Kujawa, M., \& Szymczak, C. (2014). Numerical and experimental investigation of rotational stiffness of zed-purlins connection with sandwich panels. Thin-Walled Structures, 75, 43-52.

Kwon, Y. B., Chung, H. S., \& Kim, G. D. (2006). Experiments of cold formed steel connections and portal frames. Journal of Structural Engineering, 132, 600-607.

Laine, M., \& Tuomala, M. (1999). Testing and design of gravity loaded steel purlins restrained by sheeting. Journal of Constructional Steel Research, 49, 129-138.

Li, L.-Y. (2004). Lateral-torsional buckling of cold-formed zed-purlins partial-laterally restrained by metal sheeting. Thin-Walled Structures, 42, 995-1011.

Li, L.-Y. (2009). Analyses of distortional buckling of cold-formed sigma purlins using EN1993-1-3. Journal of Constructional Steel Research, 65, 2099-2102.

Li, L.-Y., Ren, C., \& Yang, J. (2012). Theoretical analysis of partially restrained zed-purlin beams subjected to up-lift loads. Journal of Constructional Steel Research, 70, 273-279.
Liu, Q., Yang, J., \& Wang, F. L. (2015). Numerical simulation of sleeve connections for cold formed steel sigma sections. Engineering Structures, 100, 686-695.

Lucas, R. M., Al-Bermani, F. G., \& Kitipomchai, S. (1997a). Modelling of cold-formed purlin-sheeting systems: 1 full model. ThinWalled Structures, 27, 223-243.

Lucas, R. M., Al-Bermani, F. G., \& Kitipomchai, S. (1997b). Modelling of cold-formed purlin-sheeting systems: 2 simplified model. Thin-Walled Structures, 27, 263-296.

Mills, J. E., \& Laboube, R. (2004). Self-drilling screw joints for coldformed channel portal frames. Journal of Structural Enginnering, $130,8$.

Ren, C., Li, L.-Y., \& Yang, J. (2012). Bending analysis of partially restrained channel-section purlins subjected to up-lift loadings. Journal of Constructional Steel Research, 72, 254-260.

Tan, K. H., Seah, L. K., \& Fok, S. C. (1996). Connections in coldformed thin-walled structures. Computers \& Structures, 60, 4.

Vieira, L. C. M., Malite, M., \& Schafer, B. W. (2010). Simplified models for cross-section stress demands on $\mathrm{C}$-section purlins in uplift. Thin-Walled Structures, 48, 33-41.

Vrany, T. (2002). Torsional restraint of cold-formed beams provided by corrugated sheeting for arbitrary input variables. In Eurosteel the $3 r d$ European conference on steel structures. Coimbra, Portugal.

Vrany, T. (2006). Effect of loading on the rotational restraint of coldformed purlins. Thin-Walled Structures, 44, 1287-1292.

Yang, J., \& Liu, Q. (2012a). An experimental study into flexural behaviour of sigma purlins attached with roof sheets. Engineering Structures, 45, 481-495.

Yang, J., \& Liu, Q. (2012b). Sleeve connections of cold-formed steel sigma purlins. Engineering Structures, 43, 245-258.

Ye, Z.-M., Kettle, R., \& Li, L.-Y. (2004). Analysis of cold-formed zed-purlins partially restrained by steel sheeting. Computers \& Structures, 82, 731-739.

Ye, Z.-M., Kettle, R., Li, L.-Y., \& Schafer, B. (2002a). Buckling behavior of cold-formed zed-purlins partially restrained by sheeting. Thin-Walled Structures, 40, 853-864.

Ye, Z. M., Kettle, R. J., Li, L. Y., \& Schafer, B. W. (2002b). Buckling behaviour of cold-formed zed-purlins partially restrained by steel sheeting. Thin-Walled Structures, 40, 853-864.

Yuan, W.-B., Cheng, S., Li, L.-Y., \& Kim, B. (2014). Web-flange distortional buckling of partially restrained cold-formed steel purlins under uplift loading. International Journal of Mechanical Sciences, 89, 476-481.

Zhao, C., Yang, J., Wang, F., \& Chan, A. H. C. (2014). Rotational stiffness of cold-formed steel roof purlin-sheeting connections. Engineering Structures, 59, 284-297.

Zhu, J., Chen, J., \& Ren, C. (2013). Numerical study on the moment capacity of zed-section purlins under uplift loading. In The 2013 world congress on advances in structural engineering mechanics (ASEM 13). Jeju, Korea. 